\title{
Defining enabling technology for aortic valve replacement
}

Vinay Badhwar, MD

See related article on pages 1578-83.

In this issue of the Journal, Permanyer and colleagues ${ }^{1}$ eloquently describe technical nuances gleaned from their single-center, 60-patient experience with the 3F-Enable aortic valve prosthesis (Medtronic, Inc, Minneapolis, Minn). This prothesis is an equine pericardial valve mounted on a thermally expandable nitinol frame with Conformité Européenne (CE-mark) approval, and is currently not commercially available in the United States.

The unprecedented progress with transcatheter aortic valve replacement (TAVR) has spurred outcome improvement of surgical aortic valve replacement (AVR) in moderate- to high-risk patients. A surge of experience with sutureless and rapid-deployment (RD) aortic prostheses can potentially offer additional outcome enhancement to conventional AVR..$^{1-7}$ In addition to the $3 \mathrm{~F}$ Enable, other valves with accelerating investigational experience and only CE-mark approval include the Perceval S (Sorin Group, Saluggia, Italy) and the Intuity Valve System (Edwards Lifesciences, Irvine, Calif). Sutureless or RD valves hold promise for advancing AVR through improved effective orifice area, implant expediency, and facilitation of minimally invasive approaches.

In the current report, ${ }^{1}$ the experienced authors note an impressive mean cross-clamp time of 35.4 minutes, and cardiopulmonary bypass time of 49.8 minutes. They transparently describe a learning curve for the valve, averaging a 43-minute ischemic time for their first 10 patients, and 34 minutes for their last 10 patients, compared with 58 minutes for temporally performed conventional AVR. The device had excellent hemodynamics with an 8.4- $\mathrm{mm} \mathrm{Hg}$ mean gradient devoid of patient-prosthesis mismatch. However, a mild or greater paravalvular leak (PVL) rate of $8.3 \%$ (5 of 60) was observed. One case of severe PVL required early reoperation for ventricular migration that the authors

\footnotetext{
From the Department of Cardiothoracic Surgery, University of Pittsburgh, Pittsburgh, Pa.

Disclosure: V.B. discloses no financial or commercial support other than his institution being engaged in clinical trial investigation with the Intuity Valve System by Edwards Lifesciences.

Received for publication March 3, 2015; accepted for publication March 4, 2015; available ahead of print April 9, 2015

Address for reprints: Vinay Badhwar, MD, Department of Cardiothoracic Surgery, University of Pittsburgh, 200 Lothrop St, C-724, Pittsburgh, PA 15213 (E-mail: badhwarv@upmc.edu).

J Thorac Cardiovasc Surg 2015;149:1584-5

$0022-5223 / \$ 36.00$

Copyright (c) 2015 by The American Association for Thoracic Surgery

http://dx.doi.org/10.1016/j.jtcvs.2015.03.007
}

felt was a result of annular overdebridement. Acute prosthesis repositioning was required in $10 \%$ (6 of 60), 2 with repeat cross-clamping. This moderate-risk cohort, with a mean logistic EuroScore of 13.8, and a EuroScore II of 3.8, had a 30-day operative mortality of $6.6 \%$, and a stroke rate of $3.3 \%$.

In a similar series by Eichstaedt and colleagues, ${ }^{2} 120$ moderate- to highrisk patients underwent AVR with the $3 \mathrm{~F}$ Enable valve. Repeat cross-clamping for PVL was required in 8.3\% (10 of 120 ), and the 30-day mortality was $6.7 \%$. For isolated AVR, the mean ischemic time was 37 minutes, and 30-day mortality was $1.4 \%$ ( 1 of 71 ). Engleberger and colleagues $^{3}$ reported multicenter, midterm outcomes with the $3 \mathrm{~F}$ Enable in 141 patients, noting maintenance of superb 7.7-mm Hg gradients at 5 years, although $2.8 \%$ (4 of 141) required reoperation within 6 months for significant PVL. Miceli and colleagues ${ }^{4}$ reported 281 minimally invasive Perceval S implants in low- to moderate-risk patients with a median logistic EuroScore of 8, with cross-clamp and bypass times of 48 and 81 minutes, respectively, a mortality of $0.7 \%$, a stroke rate of $1.8 \%$, and a PVL rate of $1.8 \%$.

Sutureless and RD technology enables implant expediency and excellent midterm hemodynamic performance, but can it consistently deliver procedural outcomes on a par with conventional AVR? To estimate a comparator for the several, single-armed descriptive reports on sutureless valves recently published, let us examine contemporaneous conventional AVR outcomes from The Society of Thoracic Surgeons Adult Cardiac Surgery Database. A total of 44,969 isolated AVR operations were performed between January 2013 and June 2014. From January 1 to December 31, 2013, a total of 30,241 isolated AVRs were performed with median cross-clamp and bypass times of 72 and 98 minutes, respectively, with a risk-adjusted 30-day operative mortality of $2.3 \%$, and a stroke rate of $1.4 \%$. From January 1 to June 30,2014 , a total of 14,728 isolated AVRs were performed with median cross-clamp and bypass times of 72 and 97 minutes, respectively, a risk-adjusted mortality rate of $2.2 \%$, and a stroke rate of $1.1 \%$.

In a recent multicenter randomized trial of low-risk patients undergoing sternotomy AVR or minimally-invasive Intuity valve implants, Borger and colleagues ${ }^{5}$ noted improved hemodynamic performance with the Intuity over conventional bioprostheses, noninferior mortality and morbidity, and a modest 13 minute mean cross-clamp 
time reduction. Sutureless and/or RD valves present unique advantages of hemodynamic performance that have the potential to improve durability but this can be proven only through further longitudinal investigation. Disadvantages of stent distortion, PVL, and implant misadventures need to be minimized if consistent outcomes are to be realized. Permanyer and colleagues ${ }^{1}$ laudably outline technical suggestions specific to their 3F-Enable experience: (1) Avoid complete annular debridement; a homogenous 2-mm rim of calcium may enhance anchoring; (2) Make the transverse aortotomy $4 \mathrm{~cm}$ above the sinotubular junction, to avoid aortic closure difficulties; (3) Avoid proximal aortic anastomoses if concomitant coronary artery bypass grafting is performed.

Analogous to TAVR, sutureless or RD prostheses employ a platform of radial force, anchoring in the aortic annulus with or without added subannular or supra-annular stabilization. In contrast to TAVR, sutureless and RD prosthesis implantation involves diseased leaflet excision, theoretically reducing PVL and late thromboembolic complications, ${ }^{6}$ although the incoming generation of PVL-reducing TAVR devices may hamper that argument. ${ }^{8}$ It seems that sutureless and/or RD enabling devices may be an ideal choice in small, calcified roots, or complex multiprocedures, when ischemic time may be a more subtly relevant factor, ${ }^{7}$ although more investigation is needed. The attestation that sutureless and RD technology improves outcomes by facilitating minimally invasive AVR and operating-room extubation should be tempered in an era in which this can be achieved even with conventional operations.

It seems possible that the consistently low sutureless and $\mathrm{RD}$ gradients and optimal effective orifice area may soon result in durable advantages compared with conventional stented prostheses. However, the true value of any new treatment is defined as outcome performance relative to cost. ${ }^{10}$ At triple the implant price, future studies utilizing activity-based costing or similar means may be helpful to demonstrate that this exciting enabling AVR technology provides durable outcomes and value, compared with existing techniques.

\section{References}

1. Permanyer E, Estigarribia AJ, Ysasi A, Herrero E, Semper O, Llorens R. The $3 f$ Enable sutureless bioprosthesis: Early results, safeguards, and pitfalls. J Thorac Cardiovasc Surg. 2015;149:1578-83.

2. Eichstaedt HC, Easo J, Härle T, Dapunt OE. Early single-center experience in sutureless aortic valve implantation in 120 patients. J Thorac Cardiovasc Surg. 2014; 147:370-5.

3. Englberger L, Carrel TP, Doss M, Sadowski J, Bartus K, Eckstein FF, et al. Clinical performance of a sutureless aortic bioprosthesis: five-year results of the 3f Enable long-term follow-up study. J Thorac Cardiovasc Surg. 2014; 148:1681-7.

4. Miceli A, Santarpino G, Pfeiffer S, Murzi M, Gilmanov D, Concistré G, et al. Minimally invasive aortic valve replacement with Perceval S sutureless valve: early outcomes and one-year survival from two European centers. J Thorac Cardiovasc Surg. 2014;148:2838-43.

5. Borger MA, Moustafine V, Conradi L, Knosalla C, Richter M, Merk DR, et al. A randomized multicenter trial of minimally invasive rapid deployment versus conventional full sternotomy aortic valve replacement. Ann Thorac Surg. 2015;99: $17-25$.

6. Santarpino G, Pfeiffer S, Jessl J, Dell'aquila AM, Pollari F, Pauschinger M, et al. Sutureless replacement versus transcatheter valve implantation in aortic valve stenosis: a propensity-matched analysis of 2 strategies in high-risk patients. J Thorac Cardiovasc Surg. 2014;147:561-7.

7. Minh TH, Mazine A, Bouhout I, El-Hamamsy I, Carrier M, Bouchard D, et al. Expanding the indication for sutureless aortic valve replacement to patients with mitral disease. J Thorac Cardiovasc Surg. 2014;148:1354-9.

8. Généreux P, Head SJ, Hahn R, Daneault B, Kodali S, Williams MR, et al. Paravalvular leak after transcatheter aortic valve replacement: the new Achilles' Heel? A comprehensive review of the literature. J Am Coll Cardiol. 2013;61: 1125-36.

9. Badhwar V, Esper S, Brooks M, Mulukutla S, Hardison R, Mallios D, et al. Extubating in the operating room after adult cardiac surgery safely improves outcomes and lowers costs. J Thorac Cardiovasc Surg. 2014;148:3101-9.

10. Porter ME. What is value in health care? N Engl J Med. 2010;363:2477-81. 